\title{
Analysis of GSTM1 Deletion on Adult Pulmonary Tuberculosis Patients
}

\author{
I Gusti Ayu Artini, ${ }^{1}$ I Gusti NgurahBagus Artana ${ }^{2}$ \\ ${ }^{1}$ Pharmacology Department, Medical Faculty, Udayana University, Indonesia \\ ${ }^{2}$ Department of Internal Medicine, Medical Faculty, Udayana University, Indonesia
}

\begin{abstract}
It has been widely known that tuberculosis treatment might cause mild to severe side effects. One of which is hepatotoxic effect, that might potentially serious and might cause acute liver failure. Hepatoxicity incidence in worldwide has reached $48 \%$ in many countries. One of the responsible factor contributing to this is genetical variation on drug metabolizing enzyme for antituberculosis, including GSTM1. Unfortunately, there's no enough evidence regarding distribution of GSTM1 deletion in Indonesia. Meanwhile, the proportion of GSTM1 null in many countries werevaries, reached 43-46\%. This study aimed to identify the deletion of GSTM1 on tuberculosis patient receiving antituberculosis. GSTM1 deletion identification was conducted using PCR techniques. The proportion of GSTM1 null genotype in this study was $71.4 \%$.
\end{abstract}

Keywords: GSTM1 null, deletion, antituberculosis liver injury

\section{Introduction}

Until now tuberculosis still become problem in many developing countries including Indonesia. It has been widely known that tuberculosis treatment might cause mild to severe side effects. One of which is hepatotoxic effect, that might potentially serious and might cause acute liver failure. Hepatotoxicity incidence regarding antituberculosis use in tuberculosis patient in many countries have shown varied number. The proportion in Brazil were $15.6 \%$ whereas the proportion in China and India were ranging between 14$48 \% .{ }^{1,2,3,4,5,6}$

One of the contributing factor known to be reponsible for hepatoxicity incidence was genetical variation on antituberculosis-metabolizing enzyme, including GSTM1, NAT2 and CYP2E1. ${ }^{3,7,8,9,10}$ Genetic variation mostly found on GSTM1 was deletion. This polymorphism has already studied in many countries worldwide, but the result were varies. Afterall most studies reported that GSTM1 polymorphism were significantly related to hepatoxicity incidence. Unfortunately in Indonesia there was no adequate studies regarding the distribution of GSTM1 polymorphism. That's why it was very important to investigate the proportion of GSTM1 deletion on pulmonary tuberculosis patient.

\section{Methods}

This study was a cross sectional study. The subjects were selected from adult pulmonary tuberculosis patients that attended pulmonology outpatient clinic of Sanglah Hospital, using consecutive sampling thechnique. This study was approved by Ethical Committee of Sanglah Hospital. DNA sample of patient were isolated using guanidine isothiocyanatemethod from $5 \mathrm{~mL}$ ofwhole blood. Identification of GSTM1 deletion was performed using PCR technique via coamplification of GSTM1 and $\beta$-globin. Forward and reverse primer for $\beta$ globin were 5'-GAA GAG CCA AGG ACA GGT AC-3' and5'-CAA CTT CAT CCA CGT TCA CC-3', respectively.Forward and reverse primerfor GSTM1 were 5'-CTG CCC TAC TTG ATT GAT GGG-3' and5'-CTG GAT TGT AGC AGA TCA TGC-3', respectively. $\mathrm{PCR}$ condition was set on initial denaturation temperature $94^{\circ} \mathrm{C}$ for 5 minutes;followed by 35 cycles of: denaturation temperature on $94^{\circ} \mathrm{C}$ for 45 seconds, annealing temperature on $55^{\circ} \mathrm{C}$ for 45 seconds, elongationtemperature on $72^{\circ} \mathrm{C}$ for 45 seconds; ended with final elongation temperature on $72^{\circ} \mathrm{C}$ for 5 minutes.Eletrophoresis using $2 \%$ agarosegel.GSTM1 null and widtype genotype were identified when 1 (268 bp) and 2 bands (268 and 215 bp) performed on visualization, respectively.

\section{Result and Discussion}

As many as 35 samples were included in the study: $60 \%$ have positive initial BTA status; $40 \%$ have negative initial BTA status. As many as $20 \%$ were also received medications other than antituberculosis along the course of treatment.

Human GSTM1 gene was located on chromosome 1. Genetic variation mostly found in GSTM1 gene was deletion. Detection of GSTM1 deletion can be performed using $\beta$ globin as internal standard. In our study, the proportion of null genotype was higher than wildtype genotype of GSTM1 (71.4\% vs.28.6\%).This was similar to the result from other studies conducted in many countries, including in China (57.9\% vs. 42.1$)$, in Japan (53.5\% vs. $46.5 \%)$, in Thailand (60\% vs. $40 \%$ ), as well as in Turkey ( $72 \%$ vs. $28 \%$ ). Contrary to our study, study conducted in Brazil has shown the dominant genotype was wild type $(56.9 \% \text { vs. } 43.1 \%)^{3,4,11,12}$ 


\section{International Journal of Science and Research (IJSR) \\ ISSN (Online): 2319-7064}

Index Copernicus Value (2015): 78.96 | Impact Factor (2015): 6.391

Table 1: Subject characteristics in wild type and null GSTM1 genotype

\begin{tabular}{|c|c|c|}
\hline Subject characteristics & $\begin{array}{c}\text { Wild type } \\
\mathrm{n}(\%)\end{array}$ & $\begin{array}{c}\text { Null } \\
\mathrm{n}(\%)\end{array}$ \\
\hline Age & $3(18.8)$ & $13(81.2)$ \\
$-<30$ years old & $7(36.8)$ & $12(63.2)$ \\
$-\geq 30$ years old & & \\
\hline Gender & $6(30)$ & $14(70)$ \\
- Male & $4(26.7)$ & $11(73.3)$ \\
- Female & $5(23.8)$ & $16(76.2)$ \\
Initial BTA status & $5(35.7)$ & $9(64.3)$ \\
- Positive & & \\
Other medication & $2(28.6)$ & $5(71.4)$ \\
- Yes & $8(28.6)$ & $20(71.4)$ \\
- No & \multicolumn{2}{|c}{} \\
\hline
\end{tabular}

GSTM1 genetic variation was assumed as one contributing factor responsible for hepatotoxic incidence due to GSTM1 role on isoniazid metabolism. As we know many factors related to hepatotoxicity regarding antituberculosis use including genetic, race, age, gender, acetylation status, type of treatment, dose of treatment, duration of treatment, alcohol consumption, comorbid disease (especially liver and renal disease) as well as interaction with other drugs. GSTM1 was responsible for phase II metabolism of isoniazid, specifically catalized the conjugation reaction. Isoniazid was a prodrug that require further metabolism into acetylisoniazid (catalized by $\mathrm{N}$-acetyltransferase) and hydrazine. Hydrazine andacetylisoniazid then will be converted into acetylhydrazine and further into diacetylhydrazine (catalized by N-acetyltransferase). Acetylhydrazine also metabolized by CYP2E1 into toxic metabolitethat will subsequently be excreted after detoxification by glutathione S-transferase (GST). ${ }^{11,13,14}$

Several studies have investigated the relationship between genetic variation on drug-metabolizing enzyme and hepatotoxicity incidence. Most have reported that GSTM1 deletion significantly related to hepatotoxicity incidence. This also have been studied in metaanalysis studies conducted by Sun et al., as well as by Cai et al.Study by Sun et al. has shown that GSTM1 nullgenotype, together with $\mathrm{c} 1 / \mathrm{c} 1$ and slow acetylator NAT2 increased the incidence of hepatotoxicity significantly. ${ }^{15}$ Similar to Sunet al. result, study by Caiet al. reported thatslow acetylator NAT2, CYP2E1*1A allele andGSTM1 nullrelated to the risk of mild hepatotoxicity. ${ }^{16}$

\section{Conclusion}

The proportion of GSTM1 null genotype in pulmonary tuberculosis patient was relatively high, $71.4 \%$.

\section{References}

[1] World Health Organization. Treatment of tuberculosis: Guidelines. $4^{\text {th }}$ edition. World Health Organization: Geneva. 2010.

[2] Lv X, Tang S, Xia Y, Zhang Y, Wu S, Yang Z, Li X, Tu D, Chen Y, Deng P, Ma Y, Chen D, Chen R, Zhan S. NAT2 genetic polymorphisms and antituberculosis drug-induced hepatotoxicity in Chinese community population. Annals of Hepatology. 2012. 11(5):700-707.
[3] Huang YS, Chern HD, Su WJ, Wu JC, Lai SL, Yang SY, Chang FY, Lee SD. Polymorphism of the Nacetyltransferase 2 gene as a susceptibility risk factor for antituberculosis drug-induced hepatitis. Hepatology. 2002. 35:883-889.

[4] Wang T, Yu HT, Wang W, Pan YY, He LX, Wang ZY. Genetic polymorphisms of cytochrome p450 and glutathione s-transferase associated with antituberculosis drug-induced hepatotoxicity in Chinese tuberculosis patients. The Journal of International Medical Research. 2010. 38:977-986.

[5] Lee SW, Chung LSC, Huang HH, Chuang TY, Liou YH, Wu LSH. NAT2 and CYP2E1 10. polymorphisms and susceptibility to first line antituberculosis druginduced hepatitis. International Journal of Tuberculosis and Lung Disease. 2010. 14(5):622-626.

[6] Bose PD, Sarma MP, Medhi S, Das BC, Husain SA, Kar P. Role of polymorphic $N$-acetyl transferase 2 and cytochrome P4502E1 gene in antituberculosis treatment-induced hepatitis. Journal of Gastroenterology and Hepatology. 2011. 26(2):312-318.

[7] Lee WM. Drug-induced hepatotoxicity. New England Journal of Medicine. 2003. 349:474-485.

[8] Navarro VJ dan Senior JR. Drug-related hepatotoxicity. New England Journal of Medicine. 2006. 354:731-739.

[9] Arbex MA, Varella MCL, deSiqueira HR, de Mello FAF. Antituberculosis drugs: drug interaction, adverse effects and use in special situations. Journal of Brasil Pneumology. 2010. 36(5):626-640.

[10] Artini IGA, Artana IGNB. NAT2 genotype pattern among tuberculosis patients receiving fixed dose combination of antituberculosis. International Journal of Science and Research. 2016. 5(1):1-3.

[11] Fukino K, Sasaki Y, Hirai S, Nakmura T, Hashimoto M, Yamagishi F, Ueno K. Effect of N-acetyltransferase 2 (NAT2), CYP2E1 and glutathione s-transferase (GST) genotypes on the serum concentrations of isoniazid and metabolites in tuberculosis patients. The Journal of Toxicological Sciences. 2008. 33(2):187195.

[12] Aydin-Sayitogu M, Hatirnaz O, Erensoy N, Ozbek U. Role of CYP2D6, CYP1A1, CYP2E1, GSTT1, and GSTM1 genes in the susceptibility to acute leukemias. American Journal of Hematology. 2006. 81:162-170.

[13] Caws M, Tho DQ, Duy PM, Lan NTN, Hoa DV, Torok ME, Chau TTH, Chau NVV, Chinh NT, FarrarJ. PCRrestriction fragment length polymorphism for rapid, low cost identification of isoniazid-resistant Mycobacterium tuberculosis. Journal of Clinical Microbiology. 2007. 45(6):1789-1793.

[14] Ramaswamy SV, Reich R, Dou SJ, Jasperse L, Pan X, Wanger a, Quitugua T, Graviss EA. Single nucleotide polymorphisms in genes associated with isoniazid resistance in Mycobacterium tuberculosis. Antimicrobial Agents and Chemotherapy. 2003. 47(4):1241-1250.

[15] Sun F, Chen Y, Xiang Y, Zhan S. Drug metabolizing enzyme polymorphisms and predisposition to antituberculosis drug-induced liver injury: a meta analysis. International Journal of Tuberculosis and Lung Disease. 2008. 12(9):994-1002.

[16] Cai Y, Yi JY, Zhou CH, Shen XZ. Pharmacogenetic study of drug-metabolizing enzyme polymorphism on the risk of antituberculosis drug-induced liver injury: a meta-analysis. Plos One. 2012. 7(10):e47769.

\section{Volume 6 Issue 1, January 2017}

